\title{
Humores poéticos: aproximaciones al humor en la poesía española de las últimas décadas
}

\section{Poetic Humors: Approaches to humor in recent Spanish poetry}

\author{
Verónica Leuci \\ Celehis, UNMDP-INHUS-CONICET \\ veroleuci@hotmail.com
}

Resumen: El trabajo propone aproximarse al controvertido cruce entre humor y poesía, un enlace polémico que a menudo ha sido omitido o desvalorizado en las aproximaciones teóricas al género, que lo vinculan más bien con el patetismo, la solemnidad o la gravedad, a partir probablemente de malas lecturas del Romanticismo. En cambio, se plantea un acercamiento a algunas de las voces más importantes de la escena poética española, a partir de las décadas de los ochenta y noventa, como Luis A. de Cuenca, Luis García Montero, Roger Wolfe y Karmelo Iribarren. Ellos plantean en sus obras diversas manifestaciones risibles, presentando humores poéticos que apuntan a búsquedas diversas, y que van de la risa a la sonrisa, de la crítica a la ternura y del desagrado a la complacencia para realizar una lectura a contrapelo de la literatura y de la realidad, a través de la lupa descarnada y la lucidez que aporta el humor.

Palabras clave: España, humor, tradiciones teóricas, género lírico, poesía de las últimas décadas. 
Abstract: The work proposes to study the polemic cross between humor and poetry, a controversial link that has often been omitted or undervalued in the theoretical approaches to the genre. Often, it has been associated with pathos, solemnity or gravity, probably based on misreading of Romanticism. Instead, we propose an approach to some of the most important voices in the Spanish poetic scene, especially from the 80's and 9o's, such as Luis A. de Cuenca, Luis García Montero, Roger Wolfe and Karmelo Iribarren. They propose in their works various laughable manifestations, presenting poetic moods that point to diverse searches: from laughter to smile, from criticism to tenderness and from dislike to complacency.

Keywords: Spain, Humor, Theoretical tradition, Lyric genre, Contemporary Poetry.

Recibido: 5 de septiembre de 2020 Aceptado: 25 de febrero de $202 \mathrm{I}$ https://dx.doi.org/I O.I 5 I 74/rv.vi4i29.57 I 

Ojo avizor,
poeta.
No vayas a caer
en la vulgaridad
de escribir
un poema divertido;
esto es muy serio,
a este club solo acceden
las eminencias
en martirología.
No vengas ora tú
a jodernos el invento
con la vida.

KARMELO IrIBARREN

\title{
Introducción: breve itinerario teórico en torno de lo risible
}

\begin{abstract}
A hablar de humor y poesía nos aproximamos a un enlace polé1 mico que pone sobre el tapete, desde el comienzo, un camino conflictivo, de puertas cerradas, controversias y lecturas sesgadas en, al menos, dos grandes esferas de pensamiento: una, en relación con sus especulaciones teóricas a lo largo de la historia, y la segunda, en su vínculo específico con el género poético. En primer lugar, en sentido general, las teorizaciones en torno a la risa presentan debilidades y exploraciones difusas o escasas a lo largo del tiempo. Beltrán Almería, un importante estudioso de la teoría estética sobre la risa, advierte en varios de sus estudios $(2002 ; 2016)$ que "cabe preguntarse por qué sabemos tan poco en torno de la risa, por qué los escritos más leídos en torno de la risa nos defraudan, por qué resulta tan difícil decir algo valioso sobre ella” (2016: 11). Es que, como prosigue el español, la supuesta alta cultura ignora la risa y los estudios aca-
\end{abstract}


démicos reducen los monumentos de la risa a la seriedad; ya desde el Humanismo la risa era ignorada por esos humanistas dogmáticos que, salvo escasas excepciones, defendían la pureza de la seriedad (Beltrán Almería, 2016: 11-12). Pero el derrotero en torno de lo reidero, como es sabido, es mucho más remoto. De hecho, como indica con ironía Andrés Barba en su trabajo La risa caníbal, "no ha pisado la tierra un solo filósofo que no se haya sentido obligado en algún momento a dar cuenta del fenómeno de la risa” (11). Desde luego, sería impensable poder dar cuenta aquí o confrontar las múltiples aproximaciones referidas a su estudio, las polémicas y posicionamientos enfrentados o las cuantiosas clasificaciones que recorren la cultura hasta nuestros días. Podemos, en cambio, destacar algunos hitos en la historia de su reflexión y algunos rasgos comunes en los que confluyen muchos de sus estudiosos, como una primera puerta de acceso a este territorio nebuloso.

En la Antigüedad, pensadores como Platón y Aristóteles, por ejemplo, reflexionaron en torno de la risa y la comedia. El primero despliega algunos de sus postulados más difundidos a través de la voz socrática en el diálogo Filebo o del placer, presentando una postura en la que se cruzan placer y sufrimiento; según las argumentaciones del filósofo, cuando nos reímos de algo ridículo en nuestros amigos mezclamos dolor con placer, puesto que la envidia -por ejemplo- es sufrimiento y es reír, placer: "esto nos hace conocer que en las lamentaciones y tragedias, no sólo del teatro, sino en la tragedia y comedia de la vida humana, el placer va mezclado con el dolor" (Platón, 1871: 98). Asimismo, la risa será mencionada en La república considerándola un exceso que debe ser evitado, buscando el equilibrio, la mesura y la templanza a través de la razón. Aristóteles, en cambio (de manera breve, ya que muchas de sus páginas se perdieron) se refiere a lo risible y la comedia en el capítulo V de su Poética. Aquí, se deja de lado la idea de sufrimiento y dolor: "lo risible es un defecto y desfiguración sin dolor ni perjuicio, 
así como la máscara cómica es algo feo y contorsionado sin dolor" (v, 43). De modo que, para Aristóteles, lo risible es una subdivisión de lo feo: un defecto, una deformación, algo "feo y contorsionado" que no implica empero dolor ni sufrimiento.

Sin embargo, las observaciones de Aristóteles en torno de la comedia -a diferencia de lo que sucede con la tragedia, perfectamente estructurada y teorizada- son sumamente fragmentarias y breves. Esta carencia ha determinado toda la tratadística posterior, y el estudio clásico sobre la risa ha sido siempre asistemático y disperso; aunque exista una tradición teórica sobre lo cómico, esta halla su origen más bien en el ámbito de la retórica (Checa Beltrán, 1999: 13). Cicerón y Quintiliano, en este sentido, destacaron la risa como un recurso clave en la retórica y la oratoria. El primero, en De Oratore especialmente -aunque también se referirá a lo cómico y su conexión con el decoro en De Officiis-expondrá una teoría de la risa, que considera un elemento fundamental del orador. La función de la risa, para Cicerón, es equiparable a la del ethos, es decir, ganar la buena voluntad del auditorio, e incluso "la risa de buena disposición puede considerarse parte del ethos" (Romano, 2001: 164). ${ }^{1}$ En "De risu", incluido en Instituciones oratorias, Quintiliano retomará las consideraciones de Cicerón y también de Demóstenes, "las dos lumbreras de la elocuencia griega y romana" (Quintiliano, VI: III). En busca del origen de la risa, recupera las reflexiones del latino para encontrar este en "alguna deformidad o fealdad": "si el objeto de la risa son los defectos ajenos, se llama gracejo; si los nuestros, necedad" (vi: III). La risa es definida por

${ }^{1}$ Indica la autora: "El ingenio, ya lo había dicho Gorgias, es un excelente instrumento para contrarrestar las pasiones que el contrincante ha despertado [...] La función de la risa puede compararse con la del ethos, luego la risa de buena disposición puede considerarse parte del ethos y la risa de mala disposición se reserva para la invectiva, que tenía su lugar en la oratoria griega y romana" (2001: 164). 
este pensador como una pasión que obliga a manifestar el interior de la persona, sin posibilidad de disimulo: la voz, el semblante, el cuerpo se ponen en movimiento sin que otro lo mueva y contra nuestra voluntad (VI: III).

En la Edad Media, si por un lado para los filósofos del cristianismo la risa era considerada una distracción y una amenaza a la hora de "llorar por los pecados del mundo y prepararse para las dichas del más allá” (Berger, 1999: 51), ${ }^{2}$ en la cultura popular, por otro -como ha estudiado Bajtín en su fundamental trabajo dedicado a Rabelais-, la risa y lo cómico proliferaron esencialmente en el Carnaval, que recupera el viejo sentido de las festividades dionisíacas: la liberación, la inversión de jerarquías, el desenfreno, la transgresión, la exaltación de los placeres, del cuerpo, etc. En el plano estético, como dice Bajtín, las estéticas serias y las estéticas de la risa han tenido siempre distinta categoría cultural, por eso, mientras las primeras -como el patetismo y el didactismo- han sido abundantemente estudiadas y comprendidas, la teoría estética en torno a la risa ha sido siempre el punto más débil (1998). Quizás, prosiguiendo con la lucidez del ruso, porque las formas literarias de la risa pertenecen a un orden más amplio, la cara alegre y festiva de un mundo bifronte. Si la cultura oficial, digna, elevada, se estaciona prioritariamente en la faz seria y solemne del mundo, en su reverso, las estéticas de la risa forman parte de una esfera vital, alegre y festiva que no es útil a los poderosos ni al poder. Como dice el citado Beltrán Almería, no marca las distancias, las anula y destruye y presenta una dimensión más igualitaria y libre del mundo (2002: 201).

${ }^{2}$ A pesar de la simplificación que realiza Berger respecto de los estudios sobre la risa en el pensamiento medieval -bastante irónica, por cierto, y que dio lugar a las réplicas de estudiosos que el propio autor introduce en una extensa nota en su libro- deben ser mencionados al menos los importantes trabajos de Tomás de Aquino referidos a la risa y al juego, como Riissibilia, Suma de Teología o Comentario a la Ética a Nicómaco de Aristóteles. 
En la Modernidad, el Elogio de la locura, de Erasmo de Rotterdam, representa una visión humanista que constituye para la mayoría de los autores una obra maestra en referencia al estudio de lo cómico. Y, más próximos a nuestros días, Descartes, Kant, Kirkegaard, Hobbes, Hegel, Richter, Lipps, Baudelaire, entre algunos de los nombres más sobresalientes de un itinerario prolífico, esparcieron a lo largo de sus obras consideraciones en torno del humor, la risa y la comicidad, hasta arribar finalmente a dos trabajos paradigmáticos: La risa (1899), de Henri Bergson, y El chiste y su relación con el inconsciente (1905), de Sigmund Freud.

En el primero de ellos, por un lado, englobada en lo que algunos autores denominan las "teorías de la superioridad", se postula una dimensión social para lo cómico, referida a "una imperfección individual o colectiva que exige una corrección inmediata. Y esta corrección es la risa" (Bergson, 2009: 68), que implica, además, un deseo de ejercer represalias frente a lo que se considera inferior o imperfecto. Según Bergson, la risa "debe tener una significación social", pues "nuestra risa es siempre la risa de un grupo": aunque se crea espontánea, la risa "siempre oculta un prejuicio de asociación y hasta de complicidad", por eso, "para comprender la risa, hay que reintegrarla a su medio natural, que es la sociedad" (2009: 14-15). Por su lado, revirtiendo las antiguas postulaciones aristotélicas sobre el carácter "indoloro" de la risa, para el francés, "no hay mayor enemigo de la risa que la emoción [...] Lo cómico, para producir todo su efecto, exige como una anestesia momentánea del corazón. Se dirige a la inteligencia pura" (2009: 13-14).

Con Freud nos encontramos con el principal representante de las teorías psicoanalíticas (también llamadas teorías de la descarga), basadas en los factores de ahorro, represión y liberación para explicar lo cómico. El placer cómico deviene del ahorro de energía psíquica realizado: el chiste y lo cómico serán para este autor mecanismos de economía psíquica. Sin embargo, existe una diferencia entre ambos, 
ya que de acuerdo con Freud el chiste halla su fuente de placer en el ahorro del gasto de cohibición y, a diferencia de lo cómico, que se descubre, el chiste siempre se inventa: "La participación de una tercera persona, a la que lo cómico es comunicado, intensifica el proceso cómico, pero no agrega a él nada nuevo. Por el contrario, el chiste precisa obligatoriamente de dicha tercera persona para la perfección del proceso aportador de placer" (1967: 162).

Más allá de las miradas plurales e incluso antagónicas en torno del humor, sus límites, manifestaciones y características, existen algunos rasgos que se repiten en muchos de los acercamientos, enunciados de maneras diferentes y desde lugares diversos. En primer término, es posible destacar su carácter privativamente humano -ya con Aristóteles y su animal ridens que, de acuerdo con J. Huizinga, "caracteriza al hombre por oposición al animal todavía mejor que el homo sapiens (17)-. Después, su universalidad y su relatividad, ya que lo que la gente considera gracioso varía de una época a otra (Berger, 1999: 11). Por su parte, como indica por ejemplo Bergson, la repetición, la inversión y, especialmente, la automatización se plantean como elementos constitutivos de la risa: nos reímos cuando algo vivo nos recuerda a una máquina, o, como dice Grothan, "en la imitación convincente, la persona imitada pierde súbitamente su identidad, lo cual es peor aun que perder la propia sombra" (1961: 29).

La ruptura o frustración de expectativas constituyen también elementos decisivos en su descripción, junto con el contraste, la contradicción y la incongruencia entre niveles o mundos posibles. De este modo, en el ya mencionado trabajo de Bergson, la "interferencia de series" representa uno de los más importantes efectos cómicos, a la que define como "toda situación es cómica cuando pertenece a dos series de hechos, absolutamente independientes y se puede interpretar a la vez en dos sentidos totalmente distintos" (74). Dentro de este paradigma, de largo aliento en la reflexión 
teórica y filosófica -que incluso se abre ya en la Antigüedad con Aristóteles, Cicerón y Horacio, se ubican algunos estudios fundamentales, entre los que se destacan por ejemplo Schopenhauer, Hutcheson, Hegel, Kirkegaard. A su vez, como uno de los trabajos fundantes respecto de la visión del humor a partir de las expectativas frustradas, se encuentra la famosa postulación de Kant, quien en Crítica del juicio teoriza la diferencia como la raíz de lo cómico: "La risa es una emoción que nace de la súbita transformación de una espera ansiosa en nada".

Como dice López Cruces, "lo cómico juega a hacer chocar el sentido y el sinsentido; lo lógico y lo ilógico [...] los hechos y las palabras; los hechos y el tono en que son contados...” (2004: 12). También Rafael Núñez Ramos, en su trabajo "Semiótica del texto humorístico", alude a un orden predecible o esperable de acontecimientos y la ruptura de ese orden en el contexto humorístico: "una desproporción, una rigidez en el comportamiento, una desviación o incoherencia con respecto al orden natural de los acontecimientos" (1984: 270). Este autor resalta en este sentido la necesidad de un enfoque semiótico del mensaje humorístico que supere la mera lectura textual y que contemple, en cambio, no solo el nivel sintáctico-funcional, sino también el semántico-pragmático, fundamental en la percepción de la pluralidad de sentidos emergentes de un texto humorístico. Las posturas de estos autores - provenientes de la filosofía, la semiótica, la crítica literaria, etc.- se inscriben dentro de una esfera mayor que, con la mayoría de los estudiosos, podemos denominar teorías de la incongruencia -con sus matices y variantes, como la teoría de la sorpresa, teoría del ingenio, teoría de la expectativa frustrada, etc.,$-{ }^{3}$ en referencia a esta idea de ruptura,

${ }^{3}$ Cfr. con el trabajo de Enrique Gallud Jardiel referido en la Bibliografía, que desarrolla breve pero muy claramente algunas de las múltiples teorías, autores y textos que se ocuparon del estudio de la teoría del humor a lo largo del tiempo. 
oposición y frustración de expectativas que las atraviesan como matriz insoslayable en la aproximación al fenómeno humorístico.

\section{Poesía y humor en la literatura: trayectoria genealógica y voces contemporáneas en España}

Ahora bien, yendo puntualmente al plano poético, como advierte con gran ironía el vasco Karmelo Iribarren citado en el epígrafe, el género lírico ha sido asociado tradicionalmente al patetismo, la seriedad, la solemnidad, probablemente por las malas lecturas del Romanticismo que vincularon lírica a verdad (tal el título de la autobiografía de Goethe, por ejemplo,) y la poesía, en consecuencia, como el canal el propicio para asentar el "estado del alma" de una subjetividad, las tesituras -generalmente patéticas, exaltadas y grandilocuentes- de un poeta. El reinado dominante de la primera persona del singular ha vinculado el discurso poético de modo mayoritario con la expresión intimista de un "yo". En las visiones más tradicionales la poesía fue concebida en este sentido desde un tenor confesional y "biografista", imprimiéndole entonces un carácter de veracidad y sinceridad, como efusión de ese sujeto que, en consecuencia, se tornaba un "sujeto ético" (Combe, 1999). ${ }^{4}$

Reflexiona con lucidez el crítico Javier Letrán al referirse al humor en poesía que, en "cuestiones poéticas, por estrictas y rigurosas razones extraliterarias, la elegía fúnebre, la circunspecta reflexión metafísica y el lamento amoroso o de cualquier otro tipo siempre han gozado a priori de mayor prestigio que las cantigas de escarnio,

\footnotetext{
${ }^{4}$ Posteriormente, sin embargo, huelga señalar que, desde posicionamientos variados, ya desde la crítica al pensamiento romántico, múltiples autores han objetado esta tendencia que ubica la poesía en el terreno de la "dicción", al refutar la idea de realidad o de veracidad de los enunciados del sujeto lírico, reivindicando en cambio su estatuto ficcional o imaginario (Mignolo, Herrstein Smith, Lázaro Carreter, Pozuelo Yvancos, etc.).
} 
las letrillas satíricas o los poemas festivos"; para continuar con una aseveración elocuente en la tradición en torno del humor y la comedia, como un guiño a la magistral novela de Umberto Eco, El nombre de la rosa: "Como si dentro de cada uno de nosotros llevásemos un severo Jorge de Burgos prohibiéndonos la risa diabólica y antipoética so amenaza de pena capital por envenenamiento" (2003: 3).

En el panorama espańol -esfera que concierne primariamente a nuestro interés- ha sido Carlos Bousońo en su famosa -y cuestionada- Teoría de la expresión poética quien estudia dicha relación, centrándose sin embargo no en el humor en sentido general sino en el chiste. En "La poesía y la comicidad”, el crítico asturiano destaca el papel preponderante del lector como co-autor de la obra, ya sea en la captación de la emoción poética como en la consecución del efecto cómico: para el primero, no obstante, es crucial su "asentimiento", en tanto que para el placer humorístico el receptor será fundamental pero a partir de su "disentimiento con tolerancia y complicidad" (296-297). Para Bousoño, poesía y chiste son fenómenos estéticos opuestos: "poesía y chiste son el anverso y reverso de una misma medalla [... Lo contrario de la poesía es el chiste” (297).

A partir de este antagonismo y exclusión aparente planteados por Bousoño entre poesía y comicidad, podemos derivar una interrogación interesante para pensar la tradición poética: ¿puede ser un mismo texto poético y humorístico? O, en otras palabras, ¿pueden coexistir en el mismo texto el que podemos denominar "placer poético" (emoción lírica, según Bousoño) y el "placer cómico" (en la terminología de Freud)? Es sabido que, a lo largo del tiempo, los géneros más explorados y asociados al humor han sido el teatro, el chiste e incluso el cuento y la novela, pero no el género poético. Se asocian a este último algunos subgéneros particulares, como el epigrama o los poemas satírico-burlescos, y algunos autores, textos o poéticas específicas - muchas veces considerados "menores"- o como parte de una tradición alternativa. 
Sin embargo, es posible reconocer a lo largo de la literatura española una extensa genealogía de textos humorísticos. Desde algunas creaciones medievales, como las serranillas del Arcipreste de Hita del Libro del Buen Amor; luego, el siglo xv da lugar a la creación de sátiras como las Coplas del Provincial, Coplas de Mingo Revulgo, Coplas de ¡Ay Panadera!, o autores de la altura del marqués de Santillana, Juan de Mena o Jorge Manrique, que incluyeron algunos textos satíricos o paródicos en los Cancioneros de Baena y de Estúniga (Cfr. López Cruces, 2004: 24). Entre los grandes poetas áureos se destaca en especial la poesía burlesca y satírico-burlesca de Quevedo, y también del Góngora de las letrillas, romances, sátiras y el Lope de Vega de La Gatomaquia, por ejemplo. Posteriormente, se reconoce el tono festivo y cómico en autores como Campoamor -considerado uno de los primeros humoristas del siglo XIX- en sus textos denominados "Doloras, humoradas y pequeños poemas", etc.

Ahora bien, en el siglo xx merece una especial atención en el llamado panorama de "anteguerra" (amén de ciertos poemas modernistas, como textos lúdicos de Valle-Inclán) el humor vanguardista y uno de sus principales representantes: Ramón Gómez de la Serna. Este autor elevó el "humorismo" a la categoría de -ismo vanguardista, exponiendo su teoría en "Gravedad e importancia del humorismo" (1928), un texto que "tendrá una impronta imborrable en varias generaciones de escritores españoles" (Llera, 2001: 462). Posteriormente, tras la Guerra Civil se reconoce en los años 40 una poesía de propensión humorística, lúdica, atravesada por pinceladas surrealistas, en el efímero grupo "Postista", con autores como Carlos E. de Ory, Chicharro o Sernesi. Luego, en la poesía social de posguerra, algunos "poetas mayores" como Blas de Otero o Gabriel Celaya introducen en sus textos algunas líneas humorísticas a través del prosaísmo, la ruptura de frases hechas, etc. Pero será en especial en los años 50, en el "medio siglo", el momento en que la poesía se renovará, a través de humor y, sobre todo, de la 
ironía, de la mano de poetas como Ángel González, Jaime Gil de Biedma e, incluso, con la "curiosa" voz, lúdica y bienhumorada, de Gloria Fuertes (Leuci, 2015).

En esta ocasión, más allá de estos nombres recortados de una tradición mayor que precisa y puede ser ampliada, proponemos leer y reconocer elementos risibles en la poesía de cuatro voces centrales de escena española de las últimas décadas, desde los 80 y 90 y hasta nuestros días: Luis García Montero, Luis A. de Cuenca, Roger Wolfe y Karmelo Iribarren. Se procura advertir en ellos tonos, estrategias, tópicos o procedimientos que actualizan el vínculo siempre complejo entre poesía y humor en sus poéticas, de maneras múltiples y alentados por búsquedas diversas.

\section{Reescrituras, juego y lirismo en García Montero}

En primer lugar, con el granadino Luis García Montero, nos situamos en el centro de la escena poética espańola a partir de los ańos 80: La otra sentimentalidad granadina, disuelta luego como grupo y proseguida por una vertiente denominada "poesía de la experiencia”, que reúne voces heterogéneas a nivel peninsular, de quien el mencionado autor es uno de sus portavoces y poetas más importantes (Iravedra, 2002; Scarano, 2019). Esta tendencia estética, como veremos, agrupó bajo su paraguas dicciones más o menos concordantes -sin obviar las disidencias, cuestión que retomaremos más adelante-, asociadas esencialmente por los hilos del realismo, la apuesta por la legibilidad, el escenario y temática urbana, la búsqueda de un lector cómplice, la conciencia de artificio del sujeto poético y de la experiencia concebida como experiencia fingida, junto con la recuperación de materiales, metros, tópicos, voces de la tradición y el gusto por los juegos intertextuales.

En este poeta, el poemario Rimado de ciudad -el título ya nos los anticipa, evocando el Rimado de palacio, texto medieval de 
López de Ayala- contiene dos de los ejercicios más originales e irreverentes en su lectura de materiales heredados, a partir de la renovación métrica e intertextual de poemas consagrados de la tradición espańola: la "Égloga de los dos rascacielos" y las "Coplas a la muerte de un colega". ${ }^{5}$ En el primero, el curioso poema fechado en 1984 retoma como anuncia su paratexto el género bucólico y, específicamente, la cristalización aurisecular de Garcilaso, con la Égloga I que funciona como hipotexto. Los elementos del texto clásico son retomados para resemantizarlos; se actualizan los actores de la tradición (Salicio y Nemoroso, quienes penan por Galatea y Elisa, respectivamente) se reemplazan por una tríada contemporánea: los dos rascacielos como los hablantes, y un único objeto de amor y pesar, esta vez, una morena "princesa urbana", que habita en el interior de uno de ellos: "Lamentaban dos dulces rascacielos / la morena razón de su desgracia, / bajo el sol del invierno. Mi ciudad / escuchaba en su voz la ineficacia / de un amor que vencido por los celos / otorga duelo y quita libertad" (109). Los locutores de esta versión sui generis en la trayectoria genérica son pues estos personajes-emblemas de la vida urbana y las grandes metrópolis:

\author{
Teléfonos alertas, \\ sirenas que la luz cruzáis veloces, \\ letreros luminosos, altavoces, \\ carteleras expertas \\ que hacéis negocios y mentís ofertas,
}

yo que acudo al amigo,

\begin{abstract}
${ }^{5}$ Aparte de estos dos poemas, el poemario expone un verdadero muestrario de moldes de la tradición, actualizados bajo las coordenadas contemporáneas de su decir poético vinculado a "La otra sentimentalidad": sonetos, décimas, tercetos, pareados, etc. Se recomienda el trabajo de Lucía Tena Morillo consignado en la bibliografía, quien realiza una lectura minuciosa sobre estas cuestiones.
\end{abstract}


os pido que cumpláis la penitencia.

Decidle que es más grave otra sentencia

que hay un mayor castigo

y ponedle mi caso por testigo (110).

“Teléfonos alertas", "sirenas", "letreros luminosos", "altavoces", "carteleras" son los mediadores invocados por el segundo rascacielos para trasmitir su caso, de mayor gravedad por tener a su amada en su interior: "como quien tiene dentro el paraíso/ y a la vez el infierno". Los elementos propios de la vida urbana se suman a la construcción de un renovado locus que reemplaza el locus amoenus de la tradición. La actualización de los rasgos bucólicos, el reemplazo paródico de los pastores, las ovejas, la verdura del prado por los rascacielos y presencias de la vida urbana y posmoderna, emplazados sin embargo en la pervivencia de la métrica clásica -la silva, la estrofa alirada, etc.- son los portadores de la mayor carga paródica o lúdica de la propuesta poética.

"Coplas a la muerte de un colega" reescribe el famoso texto manriqueño "Coplas a la muerte de su padre". En esta versión, la clave está en la desmitificación, en la luz insolente con que se retoma el hipotexto para actualizarlo tomando como centro a un personaje urbano, suburbial, actor anónimo inmerso en el contexto particular de la Espańa posfranquista de "la Movida". Resulta crucial aquí pues en la idea de contraste, entre el homenaje y la parodia: se reemplaza el personaje y los valores de la tradición, síntesis de una cosmovisión sumamente grave en el texto de Manrique del siglo xv, por este sujeto cualquiera, innominado, el "colega", como vemos por ejemplo en la estrofa 12:

No dejó ningún tesoro, dos jeringas en el suelo sin sentido, 
su navaja en deterioro, su gabán de terciopelo descosido.

Pero estuvo en la ciudad

y acaudilló los suburbios

con la suerte,

y habló de la libertad

hasta ver los ojos turbios

de la muerte.

Un sujeto, decíamos, anónimo y banalizado, inmerso en un nuevo contexto de pensamiento también desacralizado e insolente: "Nuestras vidas son los sobres / que nos dan por trabajar, / que es el morir; / allí van todos los pobres para dejarse explotar y plusvalir; / allí los grandes caudales / nos engañan con halagos / y los chicos, / que explotando son iguales / las suspensiones de pagos / y los ricos". Así, la copla de pie quebrado manriqueńa se mantiene para presentar esta propuesta en la que pervive el formato y el tono de la elegía fúnebre o planto, y rebaja en su enunciación y renovación los tópicos antiguos presentes en Manrique; en el texto tradicional las diversas estrofas discurren en torno a las cavilaciones graves sobre la muerte, desde la reflexión general, pasando por la muerte de personajes ilustres hasta llegar al caso concreto de don Rodrigo, el padre. Para ello, los versos recogen abundantes topoi de extensa estirpe, como el ubi sunt, tempus fugit, vita flumen, la vida como camino, la muerte igualadora, entre otros. En García Montero, dichos tópicos y cavilaciones continúan, pero trocados por la actualización contemporánea de personajes del mundo del espectáculo, de la música pop o rock-Marilyn, los Beatles, por ejemplo-, o, inclusive, seres anónimos de la noche y sus vicios, como el caso de este "colega" retratado en el bajo mundo de los excesos y una nocturnidad turbia. Así, se relee en clave posmoderna y bajo la rigurosa forma del pie quebrado el tema de la muerte y 
sus inquietudes y reflexiones intrínsecas, pero desde los contornos desmitificadores y rebajados que habilita la intertextualidad.

Explica el propio García Montero, en una entrevista referida a este último texto, que este libro, Rimado de ciudad, tiene un origen anecdótico y una raíz profunda: su origen surge a raíz de algunos grupos de rock de Granada ${ }^{6}$ que quisieron hacer un disco de sus poemas, y a él se le ocurrió hacer versiones de poemas clásicos, para poner entre las cuerdas de una guitarra eléctrica o encima de una batería un eco de Manrique, o Garcilaso o Góngora... Buscaba demostrar su admiración por los clásicos, pues consideraba que el conocimiento de la tradición es fundamental para poder buscar la libertad. Las "Coplas a la muerte de su colega" -según señala- son unas coplas melancólicas que tienen mucho de satírico y glosa en la primera parte, pero luego, en la segunda, se va profundizando un lirismo que sustituye a la sátira, y los versos del poema comienzan a tener enjundia poética propia (García Montero, s. d.).

Entre tradición y actualidad, entre ritmos clásicos y los ecos urbanos del punk y el rock, entre el homenaje y la parodia, la escritura de García Montero propone desdibujar las barreras controversiales entre la supuesta alta y baja cultura, entre los materiales hegemónicos y populares, en la senda del realismo posmoderno (Oleza). En medio de estos dobleces y dualidades, entre escritura y reescritura, entre inventio e intertextualidad, junto con el juego de parodia y relecturas, es posible hallar aún en esta voz la dicción

${ }^{6}$ Rimado de ciudad constituye un libro-disco publicado en 1983, editado por el Ayuntamiento de Granada. En él, los grupos rock TNT y Magic le ponen música e interpretan textos de García Montero, como las "Coplas a la muerte de su colega" y "El aguilucho". Algunos de los poemas-canciones pueden descargarse de http://rimadodeciudad.blogspot.com/. Datos técnicos: Poemas de Luis García Montero; Música de MAGIC y T.N.T; Fotografías de José Garrido y Javier Algarra; Diseńo de Juan Vida; Ideado y Producido por Mariano Maresca; Producido y Editado por Ayuntamiento de Granada, Granada, mayo, 1983. 
elegíaca propia de las voces de la tradición, tanto en los "dulces lamentares" de esos hablantes posmodernos, como en la copla manriqueña atada a la melancolía por las muertes anónimas de actores radicalmente urbanos. Es decir que parece coexistir en este autor, como nota singular, un ethos elegíaco, cargado de lirismos de factura clásica -tan del gusto del maestro Ángel González, por ciertocon la evidente desacralización contemporánea que se realiza en su poesía y en su lectura de la tradición.

\section{Humores y deshumores en la poesía de Luis Alberto de Cuenca}

Por otro, con Luis Alberto de Cuenca (Madrid, 1950) nos encontramos con un autor coetáneo al anterior, vinculado, asimismo, en la segunda etapa de su obra, por muchas afinidades poéticas y su apuesta con la legibilidad, con la poesía de la experiencia. La conexión con la música seńalada anteriormente reaparece asimismo en de Cuenca como una arista original y en realidad poco estudiada de su trayectoria autoral, como letrista de la Orquesta Mondragón en la década del $80 .^{7}$ Señala el autor al respecto, en ocasión de la edición crítica de las Canciones completas realizada por Carlos Iglesias Díez, en 2019, que esas canciones "las concebí como un contrapunto lúdico de mi obra. Nunca pensé que iban a suscitar tanto interés, ni tantos estudios sesudos y maravillosos como los que han suscitado". ${ }^{8}$

Sin embargo, como anticipamos más arriba, su poética posee características distintivas que la tornan singular y disidente respec-

${ }^{7}$ Facundo Giménez ha estudiado con agudeza esta cara poco explorada de su figura de autor en su tesis doctoral titulada "La 'línea clara' en la poesía de Luis Alberto de Cuenca (1985-2018)", defendida en 2020 en la unMDP, Argentina, aún inédita.

${ }^{8}$ Disponible en: https://www.libertaddigital.com/cultura/libros/2019-05-09/ luis-alberto-de-cuenca-el-letrista-de-la-orquesta-mondragon-1276638053/ 
to de muchos de los planteos teóricos y poéticos monterianos, por ejemplo, que el autor sortea el posicionarse en una línea poética singular a la que denomina "línea clara", tomando el rótulo de la tradición del cómic. El humor -o los humores, siguiendo la lectura de Javier Letrán (2003), un plural que recogimos como disparador de estas páginas- constituye uno de los ingredientes básicos de la poesía de madurez del madrileño, a partir de La caja de plata (1985). En su obra, la noción de humores que, de modo evidente, introduce un guiño hacia la etimología del término en sus primigenias remisiones medicinales- ${ }^{9}$ permite agrupar las múltiples tendencias a través de las cuales sus versos se entrelazan con lo risible. Así, la búsqueda humorística en de Cuenca transcurrirá de acuerdo con el mencionado crítico -cuya lectura suscribimos- entre los poemas de humor amargo (o deshumor), los poemas de humor absurdo, los poemas de humor amable y los poemas de humor paródico. Esta última veta, la más revisitada por muchos de sus coetáneos, como el ya citado García Montero, Víctor Botas, Jon Juaristi, entre otros -esa "escritura palimpsestuosa" de la que habla Darío Villanueva al referirse a los autores que escriben entre 1975

${ }^{9}$ Etimológicamente, humor alude en su acepción primigenia -que perviviría hasta el renacimiento y luego, cada vez más débil, hasta el siglo XviII- a la doctrina de los cuatro humores - "humoralismo", de acuerdo con la RAE- esbozada por Aristóteles y difundida por Hipócrates y Galeno, que repercutiría en el mundo literario. En un comienzo, "humor" - de acuerdo con la mayoría de los estudiosos- proviene del latín -umor, -oris, es decir, "líquido, humores del cuerpo humano", que deriva a su vez de -umere, y de humedad. Como señala W. Fernández Flórez, es en las Retóricas de Minturno y Escalígero donde se lee por primera vez el vocablo en conexión con la literatura; siguiendo los tecnicismos de la medicina escolástica, que la tomaba de los autores clásicos, "hacía consistir los diversos temperamentos en una repartición variable de los cuatro humores del cuerpo humano. Si el equilibrio se lograba, el temperamento era sano y perfecto (hygido), y según predominase la sangre, la linfa, la bilis o el humor negro (atrabilis) los temperamentos eran, respectivamente, sanguíneos, flemáticos, biliosos o melancólicos" (1945: 14). 
y $1990-{ }^{10}$ adquiere en su poesía un peso insoslayable que aquí solo podemos mencionar, pero que remite a una concepción poética singular donde escribir es reescribir o, citando una conocida frase de Northrop Frye: "todo poema procede de otro poema".

En su obra, el orbe intertextual remite a las procedencias más disímiles, desde la cantera remota de la Antigüedad (la Ilíada, Propercio, Catulo), pasando por la Edda, Petrarca, hasta arribar asimismo al cine (norteamericano, por ejemplo), el cómic, etc. Por su lado, los juegos intertextuales se entraman en una red en la que figuran las parodias e imitaciones burlescas, las transformaciones serias, la traducción, las falsas traducciones, etc. Vemos como ilustración de este profundo y prolífico eje los versos finales del curioso y paródico diálogo entre Príamo y Helena, de "Teichoscopia", de Animales domésticos:

"QQué bien hice estos años - piensa Príamo-

sin saber quiénes eran estos tipos!

Basta que gente así reclame a Helena

para no devolverla" $Y$ en voz alta

dice a la chica: «¿Dónde estará Paris?»

"Imagino que en la peluquería,

haciéndose las uñas y afeitándose.»

"Ayúdame a bajar de la muralla

y vamos en su busca, que os invito

a los dos a una copa en el palacio» (2006: 379).

No obstante, a pesar de ser esta una de las matrices más importantes de esta segunda etapa de su obra, existen como señalábamos otras tendencias a través de las cuales su poesía se conecta con el

${ }^{10} \mathrm{Al}$ respecto se recomienda el trabajo del especialista Juan José Lanz que citamos en la bibliografía, quien revisa con lucidez estas cuestiones en la poesía de Luis Alberto de Cuenca. 
humor y la risa, como una línea hilarante que permite asociaciones con Ionesco por ejemplo y su teatro de absurdo, en textos desopilantes con vetas surrealistas y kafkianas, "Eterno femenino", "La verdad" o el breve "Nunca más", de El hacha y la rosa:

El Diablo me dice: -Nunca más en la vida volverás a comprar boletos en la Tómbola Diocesana.- Y se ríe. Y se pierde en la niebla (1987: 50).

También recorre su poesía una vertiente de humor amable o los poemas "bienhumorados", un tipo de humor que se cruza de modo frecuente con la ternura. Esta veta asoma en poemas como "El desayuno", "La sirenita", entre otros, que procuran una sonrisa más bien benévola. Dice el primero de ellos en sus versos finales, por ejemplo:

Pero aún me gustas más, tanto que casi no puedo resistir lo que me gustas, cuando, llena de vida, te despiertas y lo primero que haces es decirme: «Tengo un hambre feroz esta mañana. Voy a empezar contigo el desayuno» (1987: 57).

Finalmente, el deshumor, el humor con un dejo amargo, se hace presente también en poemas que nacen de situaciones cotidianas y derivan hacia reflexiones o desenlaces más bien acres o sombríos. Escuchamos aquí una risa amarga sobre la que ha hablado Schopenhauer, surgida del momento en que admitimos la discrepancia entre nuestras expectativas y pensamientos y lo que nos revela la realidad (II, Comp. L, I, 8, 103). Como señala Letrán, el "humor se constituye en elemento fundamental para superar la amargura propia de una poesía de ficción autobiográfica en la que se regis- 
tran los avatares cotidianos de un personaje en el que las trivialidades y pequeńas miserias diarias terminan casi siempre imponiendo su dictadura sobre la frágil arquitectura de los sueños" (2003: 7). Por eso, la búsqueda del humorismo en su obra se constituye como una "manera idiosincrática de enfrentarse a la realidad desde las trincheras de un escepticismo profundamente vitalista" (2003: 7):

Vamos a ser felices un rato, vida mía, aunque no haya motivos para serlo, y el mundo sea un globo de gas letal, y nuestra historia una cutre película de brujas y vampiros. Felices porque sí, para que luego graben en nuestra sepultura la siguiente leyenda: «Aquí yacen los huesos de una mujer y un hombre que, no se sabe cómo, lograron ser felices diez minutos seguidos» (2006: 407). ${ }^{11}$

\section{Nuevas voces en el fin de siglo: dicciones heterodoxas y afinidades poéticas}

También en los noventa, otras voces, como es sabido, acaparan la atención de la crítica por fuera de la línea dominante de la poesía de la experiencia. En los 90, particularmente, tras el que Sánchez denomina "agotamiento de las fórmulas poéticas que habían estado desarrollándose en España desde finales de los años '70” (153), nuevos actores sobresalen en la búsqueda de soluciones poéticas y caminos renovados respecto de los anteriores: Manuel Vilas, Benjamín Prado, Luis Muñoz, Karmelo Iribarren, Roger Wolfe, Da-

${ }^{11}$ Este verso es el elegido como título para la Antología Vamos a ser felices y otros poemas de humor y deshumor de Luis Alberto de Cuenca, con prólogo de Javier Letrán, publicada en 2003 por Delegación de Cultura y Publicaciones del Excmo. Ayto. de Lucena. 
vid González, Aurora Luque, entre muchos otros. Dentro de esta última nómina, nos centraremos en esta ocasión en Roger Wolfe y en el poeta elegido para inaugurar estas páginas con el epígrafe, el vasco Karmelo Iribarren. Ellos representan dos voces afines en la cartografía poética del momento, aunque rehúyan los encasillamientos en corrientes, escuelas, grupos o, en general, los encorsetamientos que dichos marbetes conllevan.

Estas presencias representan nuevas calas en los caminos o versiones del humor que rastreamos en la poesía de fines de siglo. En un contexto sincrónico a los anteriores - deteniéndonos especialmente entonces en sus primeros poemarios publicados en los noventaWolfe en primer término constituye una figura sumamente resonante y controversial en el campo español del momento. Su irrupción representó una sacudida y un nuevo modo de decir y escribir que se aleja de las vertientes canónicas de los poetas de la experiencia y que se tradujo en polémicas críticas del más variado tenor. ${ }^{12}$

La presencia del humor será fundamental en ambos, en ocasiones a partir de una carcajada burlona y despectiva, mucho más sarcástica y ácida empero, en el marco del "humor corrosivo" de Roger Wolfe. López Merino lo define, de modo punzante, como

${ }^{12}$ López Merino ha analizado estas cuestiones en un artículo del 2005, denominado "Sobre la presencia de Roger Wolfe en la poesía española (1990-2000) y revisión del marbete 'realismo sucio". Allí se revisa de modo esclarecedor el mapa crítico y poético de la época en torno a la irrupción de esta nueva voz disonante respecto a las tendencias hegemónicas, muchas veces vinculada con el dirty realism norteamericano. Una escritura otra, diversa, revolucionaria, heterodoxa, que insiste en mantenerse a raya de grupos, tendencias, colectivos o escuelas, inscripto en una tradición personal forjada a su medida. En Iribarren se destaca también un interés pronunciado por la insularidad de una poesía al margen de etiquetas, destacando la soledad de su camino y su carrera, siempre en singular y por fuera de academias, universidades o sin el apoyo de amigos o impulsores: "Haya llegado donde haya llegado lo he hecho en solitario. No añoro pertenecer a ningún grupo" (Mengs, 2017). 
un "clarividente" (2005b; s. p.). Dentro de las características de esta clarividencia que considera definitoria de su poética, afín al existencialismo y con visos nihilistas, se halla la capacidad de dedicarse a cualquier cosa sin adherirse a ella: vivir como un extraño en todas partes - dice-, extranjero y exiliado del mundo, desarraigado de verdades y descreído de falsos ídolos como la "Literatura", con mayúscula, la "Obra", etc. Por eso muchas veces puede ser tildado de superficial, por su impavidez para no ceder jamás a la seriedad: "Sólo quien ha visto el mundo desde la desnudez y ha comprendido su vacuidad puede hablar de los grandes temas sin afectación ni presunción" (2005b: s. p.). De aquí surge naturalmente el humor en su visión de mundo; un humor que no es un ingenio buscado o rebuscado sino una carcajada natural. El propio Wolfe señala que siempre se escribe "descojonándose un poco de lo que uno mismo está escribiendo" (Apud. López Mérino, 2005b: s. p.). Por eso, señala el crítico que el humor es una vía de escape para el espíritu de seriedad, es el revés, la vuelta de tuerca, la única irreverencia posible, la única modalidad del non serviam: "El humor es el mejor antídoto contra las ínfulas de trascendencia, contra toda altisonancia, impostura, sectarismo, partidismo, gran idea o respuesta de eunucos, popes y vacas sagradas" (López Merino, 2005b).

Como un vitalista trágico -en una vereda afín a esa risa amarga de la que hablaba Schopenhauer- el sujeto poético que construye Wolfe observa, niega y ríe, desde la mueca burlona hasta la risotada que retumba y se ríe, y se distancia, de los contratos sociales, de los amores burgueses, de las prácticas urbanas tanto como de la literatura, sus actores e instituciones. Así, podemos rastrear en su obra poemas atravesados por visos humorísticos, por lo general en una búsqueda que se vale del sarcasmo, la ironía, la burla y el humor negro para lograr el efecto de risa, sorpresa y desconcierto lector: "El Doctor Roger y Mr. Wolfe visitan los juzgados" (Dias perdidos en los transportes públicos (1992), "Seguro que a Eliot no 
le pasaban estas cosas", "El borracho es un fingidor" de Hablando de pintura con un ciego (1993), "El poder de la palabra", de Arde Babilonia, "Metafísico estáis" de Mensajes en botellas rotas (1996), "Glosa a Celaya" de Cinco años de cama (1998). Estos son algunos de los títulos que podemos acotar -extraídos de libros publicados en los 90- en donde se percibe este humor lleno de tensión e incomodidad, que genera en ocasiones una risa nerviosa o una mueca de desagrado, y también, una fuerte crítica a través de la ironía, como vemos por ejemplo en "Derecho", uno de los "8 poemas en forma de artefacto" de Arde babilonia (1994), en el que resuena obviamente, en el nivel paratextual, la voz de Parra:

\author{
Tienes derecho \\ a expresar \\ libremente \\ todo aquello \\ que te esté permitido \\ decir (1994: 53).
}

Entre alguna de sus reiteradas miradas hacia la propia escritura, presentes en las muchas "Poéticas" que salpican sus páginas, podemos ver asimismo el juego de palabras y la utilización de dilogías para explotar la polisemia que habilita cierto léxico en el que se anudan connotaciones tanto literarias como sexuales: "Es tan fácil que me ha llevado veintiocho / años darme cuenta. / Una cinta virgen / en la cabeza a todas horas. / Y un buen aparato reproductor" (2007: 94). Asimismo, la mueca risible se presenta en los filosos versos finales de "Glosa a Celaya" -uno de sus textos más conocidos y citados-. Aquí, un juego intertextual recupera, para revertir en clave contemporánea y posmoderna, el famoso lema de Celaya "la poesía es un arma cargada de futuro". Este verso, síntesis de un posicionamiento poético y político dentro de los poetas sociales, cifra de la poesía 
comprometida y la utopía engagée, es trocado aquí por el vaciamiento y descreimiento iconoclasta de este outsider, que se ríe desde los márgenes del mundo del capitalismo y sus falsos ídolos:

\author{
La poesía \\ es un arma \\ cargada de futuro. \\ Y el futuro \\ es del Banco \\ de Santander (2007: 128).
}

\title{
Crítica e ironía en el humor de Iribarren
}

Karmelo Iribarren acompaña en muchos de sus textos esa mirada irreverente sobre la literatura y sus actores a la que nos hemos referido en Wolfe, en especial en alusión a los poetas mesiánicos y "superiores", supuestamente iluminados por el aura de altares sagrados, de la altisonancia y también de los críticos como cenáculo de admiradores. Leíamos con los versos citados en el epígrafe esa alusión irónica a los poetas que solo deben ser "serios", "dignos", circunspectos, con un ejercicio poético considerado por fuera de la vida y de la existencia cotidiana de cualquier hombre. El poema que antecede a "Ojo avizor", denominado "Malos tiempos" (también de La condición urbana), anticipaba ya de modo irónico la mala prensa del humor, la felicidad o incluso una sonrisa, en desmedro del gesto adusto y sesudo al que ya nos referimos desde las páginas iniciales cuando citábamos a Umberto Eco y su magistral y sombrío Jorge de Burgos: "Hay gente que es capaz / de cualquier cosa / cuando ve una sonrisa" (2015: 14).

En una senda análoga, en el poema titulado "El poeta” (1998), renueva de manera humorística y paródica un motivo recurrente 
en la poesía actual: la autorreferencia y la configuración de una imagen de poeta: "Me lo dijo / un colega, / la otra tarde: / 'Mira, tío, / como sigas así, / escribiendo / en servilletas de papel / por los bares, / acabarán colgándote / el sanbenito / de poeta, / ya verás. / Y luego, / a ver qué hostias haces" (64). "Ahora a contarlo", "Poesía española, años 80", "Los caminos el humor", asimismo, continuarán en esta línea que cruza la reflexión autopoética con un talante bastante burlón y punzante, como se observa por ejemplo en algunos versos del último de los textos citados, en referencia a un "poeta conocido" paralizado por "el miedo a la página en blanco": "trasnochado / aristócrata que pierde / el culo por salir / en cualquier medio" (25).

Es factible leer pues una risa socarrona y bastante despectiva en Iribarren, con mucho de ironía sobre todo, en particular en lo que refiere al mundillo literario y las poses e imposturas de poetas y críticos, como hemos visto en los poetas acotados. Sin embargo, no se lee en el vasco ese nihilismo o ese humor amargo y burlón que recorre como un hilo conductor la poética de Wolfe. En Wolfe, el humor es la lupa o la visión de mundo desde la que establecer la distancia escéptica y trágica frente al mundo los hombres y sus acciones. En el vasco, en cambio, parece respirarse un vitalismo mucho más marcado que, acaso, se nutre del humor, la comicidad, lo risible e incluso lo lúdico para desenmascarar actitudes, personajes o tendencias que se asoman, irrisorias y revelando su incongruencia, en su mundo poético.

La poesía española de las últimas décadas presenta dicciones variadas y polifacéticas que tornan el campo plural y coral, abierto a búsquedas y concepciones del ejercicio escriturario de la más variada índole. En el plano particular del humor -o los humores, plural que hemos elegido a lo largo del trabajo- desde retóricas singulares, apelando a recursos, procedimientos, y géneros diversos en torno de las búsquedas risibles (ironía, parodia, intertextualidad, 
juegos de palabras y diferentes figuras retóricas del campo de la anfibología, etc.), cada poeta presenta una línea y un ethos singular a la hora de asociar sus versos con lo risible. Las caras plurales del humor coexisten en tiempo y en espacio y revelan distintas políticas y poéticas de la literatura y sus posibilidades. Del juego a la burla, del humor negro a la sonrisa benevolente, los poetas acechan los dobleces de la vida y de la literatura y se entrometen por los pliegues más recónditos a través de la risa y el humor, con el lector como copartícipe de esa mirada a contrapelo, que busca los huecos por donde cuestionar y revertir los preceptos, lo establecido, los puntos fijos.

En uno de los clásicos y más importantes trabajos referidos a la risa, Mijaíl Bajtín introduce una reflexión reveladora: para el ruso, la verdadera risa no excluye lo serio, sino que "lo purifica de dogmatismo, de unilateralidad, de esclerosis, de fanatismo y espíritu categórico, del miedo y la intimidación, del didactismo, de la ingenuidad y de las ilusiones, de la nefasta fijación a un único nivel, y del agotamiento" (1989: 112). En su cruce con el territorio del humor, la poesía puede sortear dogmatismos, "espíritus categóricos", posturas, géneros, tradiciones consolidadas, canónicas, ortodoxas. De este modo, el humor y sus múltiples especies, operatorias y canales -ironía, sátira, parodia y muchos otros que se constelan en torno de él-constituyen un singular prisma y una actitud original en el asedio de las diversas búsquedas, temáticas y tópicos, para alumbrar con otra luz los temas más antiguos, y dar nuevas respuestas a las preguntas de siempre. 


\section{Bibliografía}

Aristóteles, 2011, Poética, Losada, Buenos Aires.

Bajtín, Mijail, 1998, La cultura popular en la Edad Media y en el Renacimiento: el contexto de François Rabelais, Alianza, Madrid.

Barba, Andrés, 2017, La risa caníbal. Humor, pensamiento cínico y poder, Fiordo, Buenos Aires.

, 2002, La imaginación literaria. La seriedad y la risa en la literatura occidental, Ediciones de Intervención Cultural-Montesinos, Madrid.

Beltrán Almería, Luis, 2016, Estética de la risa. Genealogía del humorismo literario, Ficticia, México.

Berger, Peter, 1999, Risa redentora. La dimensión cómica en la experiencia humana, Kairós, Barcelona.

Bergson, Henri, 2009, La risa. Ensayo sobre la significación de lo cómico, Losada, Buenos Aires.

Bousoño, Carlos, 1976, Teoría de la expresión poética, t. I y II, Gredos, Madrid.

Checa Beltrán, José, 1999, "Poética de la risa”, Scriptura, núm. 15, pp. 11-28.

Cicerón, Marco, Tulio, 2004, El orador, Alianza, Madrid.

Combe, Dominique, 1999, "La referencia desdoblada: el sujeto lírico entre la ficción y la autobiografía", en Fernando Cabo (ed.), Teorías sobre la lírica, Arco/Libros, Madrid.

de Cuenca, Luis A., 1987, El otro sueño, Renacimiento, Sevilla. , 2006, Poesía 1979-1996, Juan José Lanz (ed.), Cátedra, Madrid.

Fernández Flórez, Wenceslao, 1945, El humor en la literatura española. Discurso Ingreso RAE, 14 de mayo, pp. 1-29. 
Freud, Sigmund, 1967, "El chiste y su relación con el inconsciente", en Obras completas, vol. I, Biblioteca Nueva, Madrid, pp. 825-937.

Gallud Jardiel, Enrique, 2016, “Teorías del humor”. Disponible en: www.humorsapiens.com (Consultado: 23/10/2020]

García Montero, Luis, 1983, La otra sentimentalidad, Los pliegos de Barataria, Editorial Don Quijote, Granada. , Luis, 1993, Confesiones, Diputación de Granada, Granada. , 2015, Poesía completa (1980-2015), Tusquets, Barcelona. , 2018, "Explicación: 'Coplas a la muerte de un colega"'. Video disponible en: https://vimeo.com/302413208 (Consultado: 27/VIII/2020).

Giménez, Facundo, 2020, La 'linea clara' en la poesía de Luis Alberto de Cuenca (1985-2018), Tesis doctoral, UNMDP, mimeo.

Gómez de la Serna, Ramón, 1928, "Gravedad e importancia del humorismo", Revista de Occidente, 28 de febrero, pp. 348-360.

, 1975, "Humorismo", en Ismos, Guadarrama, Madrid, pp. 197-233.

Grotjahn, Martin, 1957, Psicología del humorismo, Morata, Madrid.

Huizinga, Johan, 1957, Homo Ludens, Emecé, Buenos Aires.

Iravedra, Araceli, 2002, “¿Hacia una poesía útil? Versiones del compromiso para el nuevo milenio", Ínsula, núms. 671-672, noviembre-diciembre, pp. 2-7.

Iribarren, Karmelo, 2015, Seguro que esta historia te suena. Poesia completa (1985-2015), Renacimiento, Sevilla.

Lanz, Juan José, 2008, "Juegos intertextuales en la poesía española actual: Algunos ejemplos". Disponible en: http://www. fuentesmemoria.fahce.unlp.edu.ar/trab_eventos/ev.405/ev.405.pdf (Consultado: 29/ VIII/2020). 
Letrán, Javier, 2003, "Prólogo: El humor en la poesía de Luis Alberto de Cuenca", en Luis A. de Cuenca, Vamos a ser felices $y$ otros poemas de humor, Ayuntamiento de Lucena, Lucena.

Leuci, Verónica, 2015, "Sobre los lomos del humor: Polisemia, crítica y humor en la poesía última de Gloria Fuertes", Pasavento. Revista de Estudios Hispánicos, Monográfico: el humor en las literaturas hispánicas contemporáneas. Nuevas perspectivas para una tradición consolidada, Juan Carlos Pueo (coord.), pp. 32.

Llera, José Antonio, 2003, "Una aproximación interdisciplinar al concepto de humor", Signa. Revista de la Asociación Española de Semiótica, núm. 12, pp. 613-629.

López Cruces, 2004, "Introducción”, en La risa en la literatura española, Biblioteca Virtual Miguel de Cervantes, Alicante, pp. 7-36. Disponible en: http://www.cervantesvirtual.com/nd/ ark:/59851/bmc0v8r2 (Consultado: 30/V/2016).

López Merino, Juan Miguel, 2005, "Sobre la presencia de Roger Wolfe en la poesía española (1990-2000) y revisión del marbete "realismo sucio"', Espéculo: Revista de Estudios Literarios. Disponible en: https://webs.ucm.es/info/especulo/numero31/ rogwolfe.html (Consultado: 1/VII/2019).

López Merino, Juan Miguel, 2005b, "Roger Wolfe: nihilismo y humor", Tonos digital: Revista de estudios filológicos, núm. 9. Disponible en: http://www.tonosdigital.es/ojs/index.php/tonos/rt/bio/454/0

Mengs, Luis, 2017, “Entrevista com Karmelo Iribarren”, Revista Contexto. Disponible en: https://ctxt.es/es/20171108/Culturas/16057/Karmelo-iribarren-poes\%C3\%ADa-ctxt-luis-mengsunamuno-celaya.htm (Consultado: 1/XII/2019).

Oleza, Joan, 1996, “Un Realismo posmoderno”, Ínsula: Revista de Letras y Ciencias Humanas, núms. 589-590, pp. 39-42. 
Platón, S. F., Filebo o del placer, Patricio de Azcárate (ed.). Disponible en: http://www.filosofia.org/cla/pla/azc03019.htm (Consultado: 29/V/2016)

Quintiliano, 1916, Instituciones oratorias, t. I y II, Imprenta de Perlado Páez y Compañía, Madrid.

Romano, Alba, 2001, "Humor y discurso político", Phaos, núm. 1, pp. 159-169.

Sánchez García, Remedios, 2018, Asi que pasen treinta años... Historia interna de la poesía española contemporánea (1950-2017), Akal, Granada.

Scarano, Laura, 2019, A favor del sentido. Poesía y discurso crítico, Valparaíso ediciones, Granada.

Schopenhauer, Arthur, 2003, El mundo como voluntad y representación, Pilar López de Santa María (ed.). Disponible en: http:// juango.es/files/Arthur-Schopenhauer---El-mundo-como-voluntad-y-representacion.pdf (Consultado: 20/VIII/2020).

Tena Morillo, Lucía, 2020, "Los metros clásicos en 'Rimado de ciudad', de Luis García Montero", Rhythmica. Revista Española de Métrica Comparada, 17, pp. 113-139.

Villanueva, Darío, 1992, "Los marcos de la literatura española (1975-1990): esbozo de un sistema", en Francisco Rico (ed.), Historia y critica de la literatura española. Los nuevos nombres: 1975-1990, Crítica, Barcelona, vol. Ix, pp. 26-38.

Wolfe, Roger, 1994, Arde Babilonia, Visor, Madrid. , 1996, Mensajes en botellas rotas, Renacimiento, Sevilla. , 2007, Días sin pan, Renacimiento, Sevilla. ,2008, Noches de blanco papel (Poesía completa 1986-2001), Huacanamo, Barcelona. 